\title{
Innovative Culture and Commercialization of Technology in Prefabricated Systems of the Construction Sector
}

\author{
Yusmeybi Castillo ${ }^{\# 1}$, Raúl J. Martelo ${ }^{* 2}$, Diofanor Acevedo*3 \\ \# Independent Researcher, Maracaibo, Zulia, Venezuela. \\ 1yusmecastill0@hotmail.com \\ * Faculty of Engineering, Faculty of Economics Sciences, \\ University of Cartagena, Cartagena, Bolívar, Colombia. \\ 2 rmartelog1@unicartagena.edu.co \\ 3diofanor3000@gmail.com
}

\begin{abstract}
The objective of this research was to determine the relationship between the innovative culture and the commercialization of technology in the prefabricated systems of the construction sector. This allows the strengthening of the innovative culture and promotes the commercialization of this new construction system, to generate competitive advantages in the market and achieve the objectives and goals of the organizations. The research was quantitative with non-experimental cross-sectional descriptive design, where a data collection instrument was designed with 54 items focused on the variables studied and the Pearson coefficient was used to determine the relationship between them. The results show a coefficient of 0.563 with a significance of 0.000 , indicative of a positive, moderate and statistically significant relationship between the innovative culture and the commercialization of technology.
\end{abstract}

Keyword - Construction, Structural components, Factories, Urbanism, Commerce

\section{INTRODUCTION}

The construction industry has evolved rapidly, due to population growth and urbanism, which have allowed the development of infrastructure worldwide and innovation in the construction sector [1]. Promote the implementation of creative solutions such as the manufacture of high quality structures, agility in the construction process and exchange of information among people involved in the project, allows to improve the innovation capacity in the construction sector [2]. This sector has gained importance due to the demand for agile constructions to meet social needs. For this reason, prefabrication has been one of the means by which construction has opted [3].

Prefabrication is the development of structural components in a factory that are then transported to the place where the installation is made and the parts are assembled to create a structure [4] [5] [6]. The construction of prefabricated has improved the quality of construction results, health and safety, reduces construction time and waste and increases the effective use of resources. [7]. According to the above, the prefabrication is considered as a better construction technology than the traditional construction technique [8].

From a technological point of view, prefabrication is seen as an access to industrialization that explores innovative processes and promotes the creation of reliable and affordable products [9]. The application of this technology has allowed the incorporation of new structures such as: stairs, facades, beams, slabs, volumetric baths and prefabricated walls [10]. The ability to innovate and market products or services provide competitive advantages in the construction sector. Innovative industries create the opportunity to market their products, which increases their sales, competitiveness and prestige [11]. Taking into account the above, construction companies should consider innovation as a habit that promotes the development of society.

However, the construction industries experience a slow process in the capacity to innovate, because they have not considered the challenges they face in adopting emerging technologies [12]; [13]. Modern industries in the construction sector must promote a capacity and innovative culture that provides them with favorable opportunities for the commercialization of their products, as well as improving safety and sustainability in society [14]. The analysis of the development of the capacities of innovation and commercialization in the construction sector, is a complex and little explored work, for which they must be considered to acquire competitive advantages in the adaptation of the new economy.

For this reason, the objective of this research is to determine the relationship between the innovative culture and the commercialization of technology in the prefabricated systems of the construction sector. This allows to boost the reach of goals in the construction industries and achieve the commercialization of this new construction system that generates a competitive advantage and a significant contribution to society. 


\section{METHODOLOGY}

The research was quantitative with non-experimental descriptive cross-sectional design. Quantitative, because the collection and analysis of data were based on numerical measurement, counting and statistical techniques [15]; non-experimental, because the variables were not manipulated, else were observed in their natural environment; cross-sectional, because the information was collected in a determined time of the investigation and the relationship between the variables was studied; descriptive, because the precision and characterization of the study event were achieved within a particular context [16].

The dimensions and indicators of the study variables Innovative Culture and Commercialization of technology were identified, which are shown in the Table 1.

TABLE I. Dimensions and indicators of the Innovative culture and Commercialization of technology

\begin{tabular}{|c|c|c|c|}
\hline Variables & Dimensions & Sub-dimensions & Indicators \\
\hline \multirow[t]{8}{*}{ Innovative culture } & \multirow{5}{*}{$\begin{array}{l}\text { Elements of the } \\
\text { innovative culture }\end{array}$} & \multirow{3}{*}{$\begin{array}{l}\text { Factors that act } \\
\text { on people }\end{array}$} & Creative Tension \\
\hline & & & Aspiration and Shared Reality \\
\hline & & & Learning \\
\hline & & \multirow{2}{*}{$\begin{array}{l}\text { Factors that act } \\
\text { on the } \\
\text { Organization }\end{array}$} & Talent management \\
\hline & & & $\begin{array}{l}\text { Management of Failure and } \\
\text { Risk }\end{array}$ \\
\hline & \multirow{3}{*}{$\begin{array}{l}\text { Barrier of innovative } \\
\text { culture }\end{array}$} & & Aptitudes \\
\hline & & & Attitudes \\
\hline & & & $\begin{array}{l}\text { Heterodoxy and questioning } \\
\text { of existing models }\end{array}$ \\
\hline \multirow{8}{*}{$\begin{array}{l}\text { Commercialization } \\
\text { of technology }\end{array}$} & \multirow{4}{*}{$\begin{array}{l}\text { Alternatives for the } \\
\text { Commercialization of } \\
\text { technology }\end{array}$} & & Product \\
\hline & & & Price \\
\hline & & & Distribution \\
\hline & & & Promotion \\
\hline & \multirow{4}{*}{$\begin{array}{l}\text { Factors that interfere } \\
\text { in the technology } \\
\text { commercialization } \\
\text { process. }\end{array}$} & & Technological Factors \\
\hline & & & Economic factors \\
\hline & & & Political factors \\
\hline & & & Human factors \\
\hline
\end{tabular}

\section{A. Population and sample}

The study population was made up of the prefabricated systems companies of the construction sector in Venezuela, which were: Metalgen 205 R.L, Fundación Biocasafundación Biocasa, Grupo Rumeli Construcciones Civiles CA, Europea de Edificios Prefabricados y Mobile Space System C.A.

Once the population was established, one of the companies was chosen as a study sample according to the following criteria: access to information, a company with more years of services or experience and the use of galvanized sheets with fiber cement joined with high density polyurethane. Taking into account the above criteria, the chosen company was MOBILE SPACE SYSTEM A.C., with the purpose of describing the current situation of the innovative culture and the commercialization of technologies in the construction sector; 4 managers were selected, 5 heads of unit and 5 supervisors.

\section{B. Data collection}

The technique used for the collection of information was the survey. This was measured using the Questionnaire data collection instrument, which consisted of 54 items with categorized questions and Likerttype scale responses, where the items were presented in a 5-point format for the analysis alternatives: Strongly agree (5), Agree (4), Neutral (3), Disagree (2) and Strongly disagree (1).

\section{Validity and reliability of the instrument}

The content of the instrument was validated through expert judgment. To this end, experts from the thematic area of study were selected, to whom a copy of the instrument was given with the objective of the research and operationalization of the variables. Each of them considered the items of the instrument to check the coherence and relevance of the same with the objective, dimensions and indicators.

With respect to the reliability of the measurement instrument, a pilot test was carried out on 15 subjects with knowledge of the study topic. Reliability was calculated using Cronbach's Alpha coefficient, using the Formula 1. 
$r_{t t}=\frac{K}{K-1}\left(1-\frac{\sum S_{i}^{2}}{S_{t}^{2}}\right)$

Wherein:

$\mathrm{K}=$ Number of items that the instrument has

$\mathrm{r}_{\mathrm{tt}}=$ Reliability coefficient

$\mathrm{S}_{\mathrm{i}}^{2}=$ Variance of the scores of each item

$\mathrm{S}_{\mathrm{t}}^{2}=$ Variance of totals

The reliability coefficient of the questionnaire that was applied to the personnel of the Management of the Mobile Space System company was 0.83 , which is considered as high reliability.

D. Data analysis

The analysis of the data was carried out based on the descriptive statistics, where absolute and relative frequencies were established for each item, which facilitated the reading, analysis and interpretation of the same. In addition, a statistical comparison scale was used (Table 2), which shows the interval and the category to which each variable, dimension and indicator of the study can be assigned.

TABLE II. Scale for the statistical analysis of the average

\begin{tabular}{|c|c|c|c|}
\hline Alternative & Level & Interval & Category \\
\hline Strongly agree (SA) & 5 & $5.00-4.21$ & Very high level \\
\hline Agree(A) & 4 & $4.20-3.41$ & High level \\
\hline Neither agree nor disagree(NA / ND) & 3 & $3.40-2.60$ & Half level \\
\hline In disagreement(ID) & 2 & $2.59-1.80$ & Low level \\
\hline Strongly disagree(SD) & 1 & $1.79-1.00$ & Very low level \\
\hline
\end{tabular}

On the other hand, a scale was used for the interpretation of the standard deviation (Table 3), in order to determine the tendency of the variables with reality and then describe them, interpret them and make decisions.

TABLE III. Scale for the interpretation of the standard deviation

\begin{tabular}{|c|c|c|}
\hline RANK & CATEGORY & INTERPRETATION \\
\hline 2.04 to 2.50 & Very High Dispersion & Very Low Reliability \\
\hline 1.53 to 2.03 & High Dispersion & Low Reliability \\
\hline 1.02 to 1.52 & Moderate Dispersion & Moderate Reliability \\
\hline 0.51 to 1.01 & Low Dispersion & High Reliability \\
\hline 0.00 to 0.50 & Very Low Dispersion & Very High Reliability \\
\hline
\end{tabular}

To determine the relationship between the variables, the Pearson correlation coefficient was used, where the scores of each variable were used, as shown in Table 4.

TABLE IV. Interpretation of the Pearson correlation coefficient

\begin{tabular}{|c|l|}
\hline Rank & Type of correlation \\
\hline $\mathrm{R}=-1$ & Perfect inverse correlation \\
\hline$-1<\mathrm{R}<0$ & Reverse correlation \\
\hline $\mathrm{R}=0$ & There is no correlation \\
\hline $0<\mathrm{R}<1$ & Direct correlation \\
\hline $\mathrm{R}=1$ & Perfect direct correlation \\
\hline
\end{tabular}

\section{III.RESULTS}

Next, the analysis of instrument data directed to the managers, heads of unit and supervisors of the Mobile Space System company is presented. The analysis of the results is developed with the interpretation of the answers obtained in the applied questionnaire, presented by indicator, dimension, sub-dimension and variable.

For the variable Innovative culture, the data provided by the questionnaire were grouped and averaged to categorize them according to the scales. The dimension analyzed was Elements of the innovative culture and the sub-dimension Factors that act on people, as evidenced in Table 5. 
TABLE V. Evaluation of the sub-dimension Factors that act on people

\begin{tabular}{|c|c|c|c|c|c|c|c|}
\hline INDICATORS & SA & A & NA / ND & ID & SD & Average & Standard deviation \\
\hline Creative Tension & $24.13 \%$ & $45.26 \%$ & $15.20 \%$ & $8.00 \%$ & $7.41 \%$ & 3.71 & 0.03 \\
\hline $\begin{array}{c}\text { Aspiration and } \\
\text { Shared Reality }\end{array}$ & $17.56 \%$ & $52.36 \%$ & $14.20 \%$ & $13.62 \%$ & $2.26 \%$ & 3.69 & 0.14 \\
\hline Learning & $54.71 \%$ & $44.12 \%$ & $1.17 \%$ & $0.00 \%$ & $0.00 \%$ & 4.54 & 0.09 \\
\hline $\begin{array}{c}\text { SUB-DIMENSION } \\
\text { AVERAGE }\end{array}$ & $32.13 \%$ & $47.25 \%$ & $10.19 \%$ & $7.21 \%$ & $3.22 \%$ & 3.98 & 0.09 \\
\hline
\end{tabular}

An average of 3.98 is evidenced for the sub-dimension Factors that act on people, which placed it at a High level of identification with a standard deviation of 0.09 , indicative of a Very low dispersion. The above, shows a favorable situation, because the factors that influence the members have the necessary stimulation to direct the company towards the achievement of goals, which allows the organization to establish an innovative culture within the same and promote the motivation, performance and ingenuity of employees. These results are related to the point made by [17], who proposes that the factors that influence workers as aspiration and shared reality, creative tension and learning, allow the members of an organization to produce creative ideas that will guarantee teamwork and apply the knowledge acquired.

According to the sub-dimension Factors that act on the organization, Table 6 is shown, which presents the results found according to the opinion of the respondents.

TABLE VI. Evaluation of the sub-dimension Factors that act on the organization

\begin{tabular}{|c|c|c|c|c|c|c|c|}
\hline INDICATORS & SA & A & NA / ND & ID & SD & Average & Standard deviation \\
\hline Talent management & $58.96 \%$ & $41.04 \%$ & $0.00 \%$ & $0.00 \%$ & $0.00 \%$ & 4.59 & 0.14 \\
\hline Management of Failure and Risk & $53.26 \%$ & $35.62 \%$ & $8.56 \%$ & $2.56 \%$ & $0.00 \%$ & 4.40 & 0.17 \\
\hline SUB-DIMENSION AVERAGE & $56.11 \%$ & $38.33 \%$ & $4.28 \%$ & $1.28 \%$ & $0.00 \%$ & 4.49 & 0.15 \\
\hline
\end{tabular}

It was observed that the average placed the sub-dimension in the Very high level category and the standard deviation in Very low dispersion. This result shows a strength for the organization regarding the indicators, because the company is willing to receive ideas and contributions from its members. In this way, it can be interpreted that the innovative production within the company depends on the creative will of the staff. In this regard, [18] argue that it is essential to increase the innovative culture within the organization in order to promote the development of new products and ideas, services or processes in the work staff.

The dimension Elements of the innovative culture is analyzed (Table 7), which compares the sub-dimensions Factors that act on people and Factors that act on the organization.

TABLE VII. Analysis of the dimension Elements of the innovative culture

\begin{tabular}{|c|c|c|c|c|c|c|c|}
\hline SUB-DIMENSIONS & SA & A & NA / ND & ID & SD & Average & Standard deviation \\
\hline Factors that act on people & $32.13 \%$ & $47.25 \%$ & $10.19 \%$ & $7.21 \%$ & $3.22 \%$ & 3.98 & 0.01 \\
\hline $\begin{array}{c}\text { Factors that act on the } \\
\text { Organization }\end{array}$ & $56.11 \%$ & $38.33 \%$ & $4.28 \%$ & $1.28 \%$ & $0.00 \%$ & 4.49 & 0.15 \\
\hline DIMENSION AVERAGE & $44.12 \%$ & $42.79 \%$ & $7.24 \%$ & $4.24 \%$ & $1.61 \%$ & 4.24 & 0.08 \\
\hline
\end{tabular}

The average ranked the dimension in the Very high level category and the standard deviation in Very low dispersion. From the above, the solidity provided by the aspects such as tension, learning, aspiration and shared reality to the innovative culture are shown, which influence the people of the organization. In addition, they are considered as the innovative source and the structure that generates the management of talent, failure and risk of an organization.

Another analyzed dimension of the Innovative culture was Barrier of innovative culture, where the results issued by the persons consulted are presented, which are reflected in Table 8. 
TABLE VIII. Evaluation of the dimension Barrier of innovative culture

\begin{tabular}{|c|c|c|c|c|c|c|c|}
\hline INDICATORS & SA & A & NA / ND & ID & SD & Average & Standard deviation \\
\hline Aptitudes & $32.56 \%$ & $49.52 \%$ & $15.32 \%$ & $2.60 \%$ & $0.00 \%$ & 4.12 & 0.12 \\
\hline Attitudes & $47.15 \%$ & $44.40 \%$ & $8.45 \%$ & $0.00 \%$ & $0.00 \%$ & 4.39 & 0.14 \\
\hline $\begin{array}{c}\text { Heterodoxy and } \\
\text { questioning of existing } \\
\text { models }\end{array}$ & $36.89 \%$ & $61.47 \%$ & $1.64 \%$ & $0.00 \%$ & $0.00 \%$ & 4.35 & 0.08 \\
\hline $\begin{array}{c}\text { DIMENSION } \\
\text { AVERAGE }\end{array}$ & $38.87 \%$ & $51.80 \%$ & $8.47 \%$ & $0.87 \%$ & $0.00 \%$ & 4.29 & 0.11 \\
\hline
\end{tabular}

It is observed that the dimension presents the average in the category Very high level and the standard deviation in Very low dispersion according to the scale of interpretation. In this way, these results reflect a favorable trend to promote the skills, attitudes, heterodoxy and questioning of existing models in the company's innovation processes, which allows the creation of new viable ideas for the development of the same and maintain the competitiveness intelligently in the market. This coincides with what was stated by [19], who express that the innovative culture present in the organization allows the promotion of market intelligence, the development of skills and the adaptation of technologies to generate new business ideas and strengthen competitiveness in the market.

For the variable Commercialization of technology, the data provided by questionnaire were grouped and averaged to categorize them according to the established scales of interpretation. Subsequently, the alternatives for the commercialization of the technology of the prefabricated systems of the construction sector are shown in Table 9 .

TABLE IX. Evaluation of the dimension Alternatives for the commercialization of technology

\begin{tabular}{|c|c|c|c|c|c|c|c|}
\hline INDICATORS & SA & A & NA / ND & ID & SD & Average & Standard deviation \\
\hline Product & $32.00 \%$ & $64.23 \%$ & $3.77 \%$ & $0.00 \%$ & $0.00 \%$ & 4.28 & 0.01 \\
\hline Price & $25.62 \%$ & $35.47 \%$ & $31.24 \%$ & $3.54 \%$ & $4.13 \%$ & 3.75 & 0.15 \\
\hline Distribution & $26.58 \%$ & $35.84 \%$ & $26.41 \%$ & $6.32 \%$ & $4.85 \%$ & 3.73 & 0.07 \\
\hline Promotion & $35.47 \%$ & $47.82 \%$ & $16.71 \%$ & $0.00 \%$ & $0.00 \%$ & 4.19 & 0.00 \\
\hline DIMENSION AVERAGE & $38.87 \%$ & $51.80 \%$ & $8.47 \%$ & $0.87 \%$ & $0.00 \%$ & 4.29 & 0.11 \\
\hline
\end{tabular}

The dimension obtained an average that categorizes it into High level and standard deviation into Very low dispersion. Therefore, it is indicated that the company has a favorable trend towards the development of alternatives for the commercialization of technology, because the products offered by the organization provide an adequate price to the market taking into account the profitability for the company, the process and distribution mechanisms and promotion. Additionally, in [20], it is stated that the companies must have knowledge regarding the domain of the product in order to correctly identify alternatives of commercialization of technology.

According to the results obtained for the dimension Factors that interfere in the technology commercialization process. They were tabulated as they are reflected in Table 10.

TABLE X. Evaluation of the dimension Factors that interfere in the technology commercialization process

\begin{tabular}{|c|c|c|c|c|c|c|c|}
\hline INDICATORS & SA & A & NA / ND & ID & SD & Average & Standard deviation \\
\hline Technological Factors & $56,32 \%$ & $35,14 \%$ & $0,00 \%$ & $8,54 \%$ & $0,00 \%$ & 4,39 & 0,01 \\
\hline Economic factors & $23,56 \%$ & $34,51 \%$ & $26,85 \%$ & $15,08 \%$ & $0,00 \%$ & 3,67 & 0,17 \\
\hline Political factors & $32,58 \%$ & $45,87 \%$ & $12,58 \%$ & $8,97 \%$ & $0,00 \%$ & 4,02 & 0,21 \\
\hline Human factors & $51,29 \%$ & $35,14 \%$ & $13,57 \%$ & $0,00 \%$ & $0,00 \%$ & 4,38 & 0,07 \\
\hline DIMENSION AVERAGE & $40,94 \%$ & $37,67 \%$ & $13,25 \%$ & $8,15 \%$ & $0,00 \%$ & 4,11 & 0,12 \\
\hline
\end{tabular}

The average of the dimension reached the category of High level and the standard deviation obtained Very low dispersion. This shows that the company considers the environment before starting the commercialization process, due it has the ability to handle factors in the internal staff, customers, office technology, salaries, finances, distributors, suppliers, competitors, as well as political forces, legal, economic, sociocultural and technological. A similar case is raised by [21], who states that it is essential to know the market to which you want to access and determine opportunities and threats in order to promote feasible business strategies.

To determine the relationship between the innovative culture and the commercialization of technology of prefabricated systems in the construction sector, Table 11 was taken into account. 
TABLE XI. Relationship between the Innovative culture and the Commercialization of technology

\begin{tabular}{|c|c|c|c|}
\hline Pearson Correlation Coefficient & Innovative Culture & Commercialization of technology \\
\hline \multirow{4}{*}{ Innovative Culture } & Pearson correlation & 1 &, $563(* *)$ \\
\cline { 2 - 4 } & Sgfnt (bilateral) &, & 0,000 \\
\cline { 2 - 4 } & $\mathrm{N}$ & 14 & 14 \\
\hline \multirow{3}{*}{$\begin{array}{c}\text { Commercialization } \\
\text { of technology }\end{array}$} & Pearson correlation &, $563\left(^{* *}\right)$ & 1 \\
\cline { 2 - 4 } & Sgfnt (bilateral) & 0,000 & 14 \\
\cline { 2 - 4 } & $\mathrm{N}$ & 14 & \\
\hline & $* *$ & & \\
\hline
\end{tabular}

According to the relationship between the Innovative culture and the Commercialization of the technology of prefabricated systems in the construction sector, the information presented in Table 11 was taken into account, which indicates that the relationship between the variables is positive, moderate and statistically significant. In this way it is evident that when the innovative culture increases, the commercialization of the technology increases in the companies of the construction sector and vice versa, which is supported by the study of [22], which states that companies in competitive technology markets must adopt an innovative thinking as a strategy for the use of resources.

Therefore, it is suggested to companies of prefabricated systems of the construction sector to implement workshops in relation to the variables studied, to strengthen the staff in knowledge, skills and abilities, as an essential element towards the processes of innovation in the company and competition in the market.

\section{IV.CONCLUSION}

The results obtained in the study for the innovative culture and commercialization of technology in the prefabricated systems of the construction sector, generated the following conclusions:

i) It was observed that the relationship between the Innovative Culture and Commercialization of technology in the prefabricated systems is positive and moderate, since it implies actions that promote the progress and the development of creative activities for the elaboration of innovative products that encourage the progress of the companies and society.

ii) The factors that act on people as Aspiration and Shared reality, creative tension and learning, present a high level of applicability within organizations, which allows the stimulation of the members towards the achievement of goals.

iii) The factors that act on organizations such as talent management, failure and risk, show a strength within the companies, since they consider the ideas and contributions of members to generate innovative solutions.

iv) The commercialization of the technology in the prefabricated systems of the construction sector, presents a high level of development of alternatives to compete in the market, because the companies offer an adequate price, considering the profitability, the processes, distribution mechanisms and the promotion.

v) Organizations have a high level of management of technological, economic, political and human factors to avoid non-compliance with laws and regulations issued by different institutions and public bodies.

\section{REFERENCES}

[1] K. Govindan, K. Shankar and D. Kannan, "Sustainable material selection for construction industry -A hybrid multi criteria decision making approach,” Renewable and Sustainable Energy Reviews, vol. 55, pp. 1274-1288, 2016.

[2] X. Xue, X. Zhang and L. Wang, M. Skitmore and Q. Wang, "Analyzing collaborative relationships among industrialized construction technology innovation organizations: A combined SNA and SEM approach,” Journal of Cleaner Production, vol. 173, pp. 265-277, 2018.

[3] P. Wong, L. Edmonson and M. Kanellopoulos, “An entropy - based study on the effectiveness of prefabrication in achieving sustainable construction,” Integrated Solutions for Infrastructure Development, pp. 1-6, 2016.

[4] R. Y. Zhong, Y. Peng, J. Fang, G. Xu, F. Xue, W. Zou and G. Q. Huang, "Towards physical internet-enabled prefabricated housing construction in Hong Kong,” International Federation of Automatic Control, vol. 48, no. 3, pp. 1079-1086, 2015.

[5] Y. Han, M. J. Skibniewski and L. Wang, "A market equilibrium supply chain model for supporting self-manufacturing or outsourcing decisions in prefabricated construction,” Sustainability, vol. 9, no. 11, pp. 2069, 2017.

[6] Q. Chen, P. H. Liu and C. T. Chen, "Evolutionary game analysis of government and enterprises during promotion process of prefabricated construction,” Journal of Interdisciplinary Mathematics, vol. 20, no. 6-7, pp. 1587-1593, 2017.

[7] M. Arif, and C. Egbu, "Making a case for offsite construction in China," Engineering, Construction and Architectural Management, vol. 17, no. 6, 536-548, 2010.

[8] D. Liu, W. Lu, Y. Niu and H. Wang, “A SCO-based tower crane system for prefabrication construction,” in Proceedings of the 20th International Symposium on Advancement of Construction Management and Real Estate, Springer, Singapore, 2017, pp. 981-991.

[9] M. Arashpour, M., Bai, Y., Aranda-mena, G., Bab-Hadiashar, A., Hosseini, R. and Kalutara, P. (2017). Optimizing decisions in advanced manufacturing of prefabricated products: Theorizing supply chain configurations in off-site construction. Automation in Construction, 84, 146-153. 
[10] C. Z. Li, J. Hong, F. Xue, G. Q. Shen, X. Xu and L. Luo, "SWOT analysis and Internet of Things-enabled platform for prefabrication housing production in Hong Kong,” Habitat International, vol. 57, pp. 74-87, 2016.

[11] J. H. Block, J. Henkel, T. G. Schweisfurth and A. Stiegler, "Commercializing user innovations by vertical diversification: The usermanufacturer innovator,” Research Policy, vol. 45, pp. 244-259, 2016.

[12] J. S. Goulding, F. Pour Rahimian, M. Arif and M. D. Sharp, "New offsite production and business models in construction: priorities for the future research agenda," Architectural Engineering and Design Management, vol. 11, no. 3, pp. 163-184, 2015.

[13] V. Yepes, E. Pellicer, L. F. Alarcón and C. L. Correa, “Creative innovation in Spanish construction firms,” Journal of Professional Issues in Engineering Education and Practice, vol. 142, no. 1, 2016.

[14] E. Goh, and M. Loosemore, "The impacts of industrialization on construction subcontractors: a resource based view," Construction Management and Economics, vol. 35, pp. 288-304, 2016.

[15] P. Leavy, Research Design: Quantitative, Qualitative, Mixed Methods, Arts-Dased, and Community-Based Participatory Research Approaches. New York: The Guilford Press, 2017.

[16] K. S. Bordens, and B. B. Abbott, Research Design and Methods: A Process Approach. New York: McGraw-Hill Education, 2018.

[17] J. Cano, Como Crear una Cultura de la Innovaciòn en las Organizaciones. España: McGraw Hill Interamericana, 2006.

[18] M. Škerlavaj, J. H. Song and Y. Lee, "Organizational learning culture, innovative culture and innovations in South Korean firms,” Expert Systems with Applications, vol. 37, no. 9, pp. 6390-6403, 2010.

[19] A. O'Cass, and L. Viet Ngo, "Market orientation versus innovative culture: two routes to superior brand performance," European Journal of Marketing, vol. 41, no. 7-8, pp. 868-887, 2007.

[20] J. Frishammar, U. Lichtenthaler and J. Rundquist, "Identifying Technology Commercialization Opportunities: The Importance of Integrating Product Development Knowledge,” Journal of Product Innovation Management, vol. 29, no. 4, pp. 573-589, 2012.

[21] V. Radulescu, "The role of market analysis in developing efficient marketing audit," International Journal of Academic Research in Economics and Management Sciences, vol. 1, no. 5, pp. 222-229, 2012.

[22] R. Stock, B., Six and N. Zacharias, "Linking multiple layers of innovation-oriented corporate culture, product program innovativeness, and business performance: a contingency approach,” Journal of the Academy of Marketing Science, vol. 41, no. 3, pp. 283-299, 2013.

\section{AUTHOR PROFILE}

Yusmeybi Castillo works at Governorate of the State of Zulia (Venezuela). Mrs. Castillo completed her master from Rafael Belloso Chacin University (Venezuela).

Raul J. Martelo works as full-time professor at the University of Cartagena (Colombia). Mr. Martelo completed his magister from Industrial University of Santander (Colombia). Mr. Martelo completed his undergraduate in Systems Engineering at the Industrial University of Santander.

Diofanor Acevedo Correa works as full-time professor in the University of Cartagena (Colombia). Dr. Acevedo completed his doctorate from University of Valle (Cali-Colombia). Mr. Acevedo completed his undergraduate in Food Engineering and Pharmaceutical Chemistry at the University of Cartagena. 